\title{
Two-color fluorescent cytosine extension assay for the determination of global DNA methylation
}

\author{
Gu Zhou' ${ }^{1}$, Craig Parfett ${ }^{1}$, Cathy Cummings-Lorbetskie², Gong-Hua Xiao², and Daniel Desaulniers ${ }^{2}$ \\ ${ }^{1}$ Mechanistic Studies Division, Environmental Health Science and Research Bureau, HECSB, Health \\ Canada, Ottawa, Canada and ${ }^{2}$ Hazard Identification Division, Environmental Health Science and \\ Research Bureau HECSB, Health Canada, Ottawa, Canada
}

BioTechniques 62:157-164 (April 2017) doi 10.2144/000114533

Keywords: methylation sensitive restriction enzyme; dual label; accuracy; precision

Supplementary material for this article is available at www.BioTechniques.com/article/114533.

Here, we present a DNA restriction enzyme-based, fluorescent cytosine extension assay (CEA) to improve normalization and technical variation among sample-to-sample measurements. The assay includes endlabeling of parallel methylation-sensitive and methylation-insensitive DNA restriction enzyme digests along with co-purification and subsequent co-measurement of incorporated fluorescence. This non-radioactive, two-color fluorescent CEA (TCF-CEA) was shown to be a relatively rapid and accurate, with 3-fold greater precision than the one-color CEA. In addition, TCF-CEA provided an index of global DNA methylation that was sensitive to differences $>5 \%$. TCF-CEA results were highly correlated with LUminometric Methylation Assay (LUMA) results using human liver cell lines (HepG2, HepaRG, HC-04) as well as a human liver primary cell culture. Hypomethylation was observed in cells treated with the de-methylating agent 5-aza-2'deoxycytidine. These results demonstrate that TCF-CEA provides a simple method for measuring relative degrees of global DNA methylation that could potentially be scaled up to higher-throughput formats.

Changes in patterns and degrees of regional or global cytosine methylation in DNA may be predictive indicators of cancer risk $(1,2)$ and are prevalent features of the disease, where they are thought to contribute to tumor formation (3-6). There is concern that such changes can result from nutritional conditions or environmental exposure (7-9).

Many techniques exist to determine global cytosine methylation levels in genomic DNA, each with specific advantages, disadvantages, and areas of applicability (10,11). Restriction enzyme-based methods depend upon the ability of certain enzymes to distinguish DNA recognition sites with methylated or unmethylated CpGs. These methods are relatively inexpensive and rapid. One commonly assayed restriction site, the sequence CCGG, which is cut by the isoschizomers
Hpall and Mspl, accounts for $8 \%$ of $\mathrm{CpG}$ sites in the human genome (12); among these, 21\% are in $\mathrm{CpG}$ islands that are predominantly unmethylated and can be cut by Hpall, while 79\% are in non-CpG island DNA (13), in which CpG residues are predominantly methylated and not digested by Hpall $(14,15)$. The wide distribution of the CCGG sequence in euchromatin and heterochromatin can therefore provide an indicator of the global cytosine-methylation level in a cell or tissue sample.

The extent of methylation of $\mathrm{CpG}$ sites in restriction enzyme cleavage sites can be measured using the cytosine extension assay (CEA), first described in 1999 by Pogribny et al. (16). This assay is based on the use of methylation-sensitive restriction endonucleases (Hpall, Acil, BssHII) that leave a 5'-guanine overhang after DNA cleavage, which can then be extended using DNA polymerase and $\left[\mathrm{H}^{3}\right] \mathrm{dCTP}$ and detected by scintillation counting, with normalization of samples based on DNA content. A modification using biotin-dCTP to extend the cut sites was described later (17). Here, DNA methylation was defined as the ratio of cutting by the methylationsensitive restriction endonuclease $\mathrm{Hpall}$ and its methylation-insensitive isoschizomer, Mspl. The signal intensity of Mspl cleavage served as a reference to normalize variable Hpall-cutting expected among experimental or clinical DNA samples. The modified assay also employed binding of the incorporated biotin-dCMP residues to streptavidin-alkaline phosphatase, reaction with an alkaline phosphatase substrate, and subsequent spectrophotometric signal detection to quantify the extent of the two separate restriction enzyme digests. Similarly, the CpGlobal assay (18) makes

\section{METHOD SUMMARY}

The two-color fluorescent cytosine extension assay (TCF-CEA) is an internally referenced global DNA methylation assay that consists of end-labeling parallel methylation-sensitive and methylation-insensitive DNA restriction enzyme digests along with co-purification and subsequent co-measurement of incorporated fluorescence. TCF-CEA was able to detect small global methylation differences between human cell lines. 
use of neuravidin-horseradish peroxidase and a luminescent chemical reaction to detect the incorporated biotin end-label.

Here, we describe a two-color fluorescent CEA (TCF-CEA), consisting of Hpall/Mspl restriction cleavage followed by overhang extension with separate incorporation of two different fluorescently labeled-dCTP nucleotides to more directly measure extension products. TCF-CEA has the original advantages of restriction enzyme-based methods-it is relatively rapid and inexpensive-while improving accuracy and precision by providing better data normalization compared with the one-color version of the assay. The applicability of TCF-CEA was demonstrated by comparing global DNA methylation levels in four human hepatic cell types, as well as in hepatocytes treated with a DNA methyltransferase inhibitor; performance was compared with the LUminometric Methylation Assay (LUMA), which uses pyrosequencing technology to detect nucleotide extension (19).

\section{Materials and methods}

Two-color fluorescent

cytosine extension assay

An aliquot of a concentrated genomic DNA stock from each biological sample was diluted to $50 \mathrm{ng} / \mathrm{\mu l}$ immediately prior to the start of the protocol to facilitate even distribution to microplate wells. The diluted DNA was digested in CutSmart Buffer for 30 min with a 10-fold excess of either the methylation-sensitive enzyme Hpall or the methylation-insensitive enzyme Mspl, according to the manufacturer's protocol (enzymes purchased from New England Biolabs, Beverly, MA). A second portion of diluted DNA was incubated without restriction enzyme as a background control. Nucleotide extension reactions were performed separately in $25 \mu$ reaction mixtures containing $200 \mathrm{ng}$ of digested or undigested DNA (200 ng represents $~ 34,000$ human diploid cells, given an estimated $6 \mathrm{pg}$ of DNA per cell), $1.0 \mathrm{mM} \mathrm{MgCl}, 5$ pmol of Alexa-647-dCTP (for Hpall-cut DNA in one reaction) or Alexa-555-dCTP (for Mspl-cut DNA in the other reaction) (Invitrogen, Carlsbad, CA), 1x PCR Buffer II and $0.5 \mathrm{U}$ AmpliTaq DNA polymerase (Perkin Elmer, Foster City, CA). The 4 extension reactions were incubated at $56^{\circ} \mathrm{C}$ (optimal temperature) for $2 \mathrm{~h}$ (incorporation plateau), stopped with high-salt buffer, then combined in pairs (an undigested pair and a digested pair) and

Fluorescent Cytosine Extension Assay Protocols

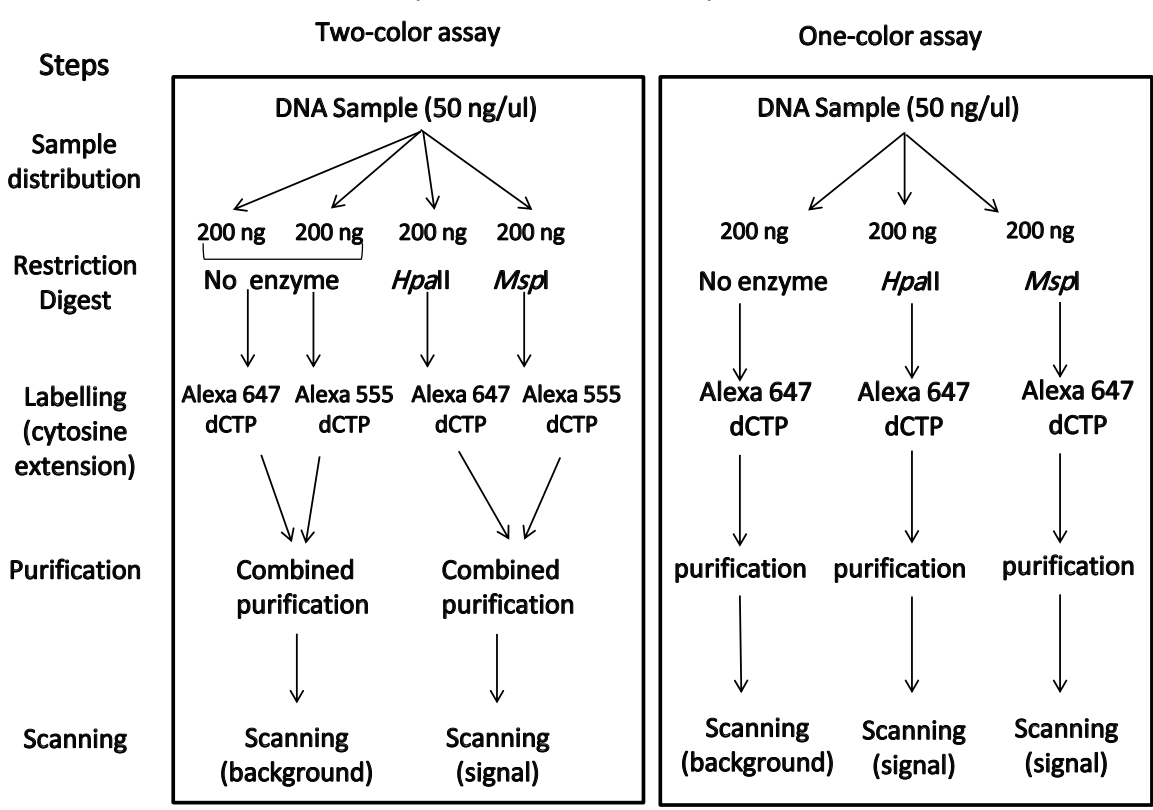

Figure 1. Schematic diagrams of the two fluorescent cytosine extension assay (CEA) protocols used in this study. Each extension reaction of restriction enzyme-digested DNA with a fluorescent dCTP was accompanied by a reaction with uncut DNA in order to show sample-specific background incorporation due to nicks, gaps, or staggered ends in the genomic DNA extracts, as well as any systematic carry-over of unincorporated nucleotide.

purified using the BioPrime Plus Purification Module (Invitrogen). In some experiments, eluted DNA fragments were re-purified with a G-50 micro column (GE HealthCare Life Sciences, Chicago, II) to further reduce the unincorporated nucleotide background (up to 8-fold further reduced compared with single-step purification). Fifteen microliters of eluted solution from each sample (from 75 $\mu \mathrm{l}$ total and containing $~ 80 \mathrm{ng}$ of doublelabeled DNA) was placed into separate wells of a 96-well glass-bottom microwell plate (Corning Incorporated, Corning, NY).

One-color assays contained 5 pmol of Alexa-647-dCTP, and the 3 reactions (background uncut, Mspl-cut, and Hpall-cut DNA) were purified separately. Five microliters of eluted solution from each sample was placed into separate wells of a 384-well glass-bottom microwell plate (Matrical Bioscience, Spokane, WA).

Plates were scanned using a Typhoon flatbed laser scanner (GE HealthCare Life Sciences) (633 nm excitation and 670 $\mathrm{nm}$ emission filter for Alexa 647; 532 nm excitation and $580 \mathrm{~nm}$ emission filter for Alexa 555) and quantified with ImageQuant software (GE HealthCare Life Sciences), carefully masking out well-wall reflections. Mspl channel intensity was used as a reference to normalize the Hpall channel intensity; the normalized Hpall intensity indicated the relative DNA methylation level between experimental and standard DNA samples. A detailed protocol is available in the Supplementary Material.

LUMA assay

Genomic DNA (600 ng) was digested in a 30- $\mu$ l volume, with either Hpall/EcoRI or Mspl/EcoRI, in Fermentas Tango buffer (Thermo Fisher Scientific, Burlington, ON), and $15 \mathrm{U}$ of each enzyme (50-100,000 U/ $\mathrm{mL}$ ). After incubation for $4 \mathrm{~h}$ at $37^{\circ} \mathrm{C}$, the reaction was stopped by incubation at $65^{\circ} \mathrm{C}$ for $20 \mathrm{~min}$ and then diluted with $30 \mu \mathrm{l}$ pyrosequencing annealing buffer (Qiagen, Toronto, ON, Canada). Triplicate $20 \mu \mathrm{l}$ DNA samples were pyrosequenced using Pyromark Gold Q96 reagents (Qiagen) on a Pyromark Q96MD system operated by version 1.0 software (Qiagen). Peak height values were exported to spreadsheet software for analysis. From a modified dispensation order of GTGTCACATGTG (20), the last four peak heights, TGTG, were used to estimate the degree of digestion by EcoRI ( $\Sigma$ T peak heights) and Mspl or Hpall ( $\Sigma G$ peak heights). Nucleotide dispensation following this order fills in any nonspecific DNA overhangs and reduces background signal by dispensing all four nucleotides (A, C, G, and T) preceding the TGTG analysis peaks. The Hpall/Mspl digestion ratio was calculated by the formula (Hpall $\Sigma \mathrm{G} / \Sigma \mathrm{T}$ )/ (Mspl $\Sigma \mathrm{G} / \Sigma \mathrm{T}$ ), where Hpall $\Sigma \mathrm{G} / \Sigma \mathrm{T}$ and Mspl 

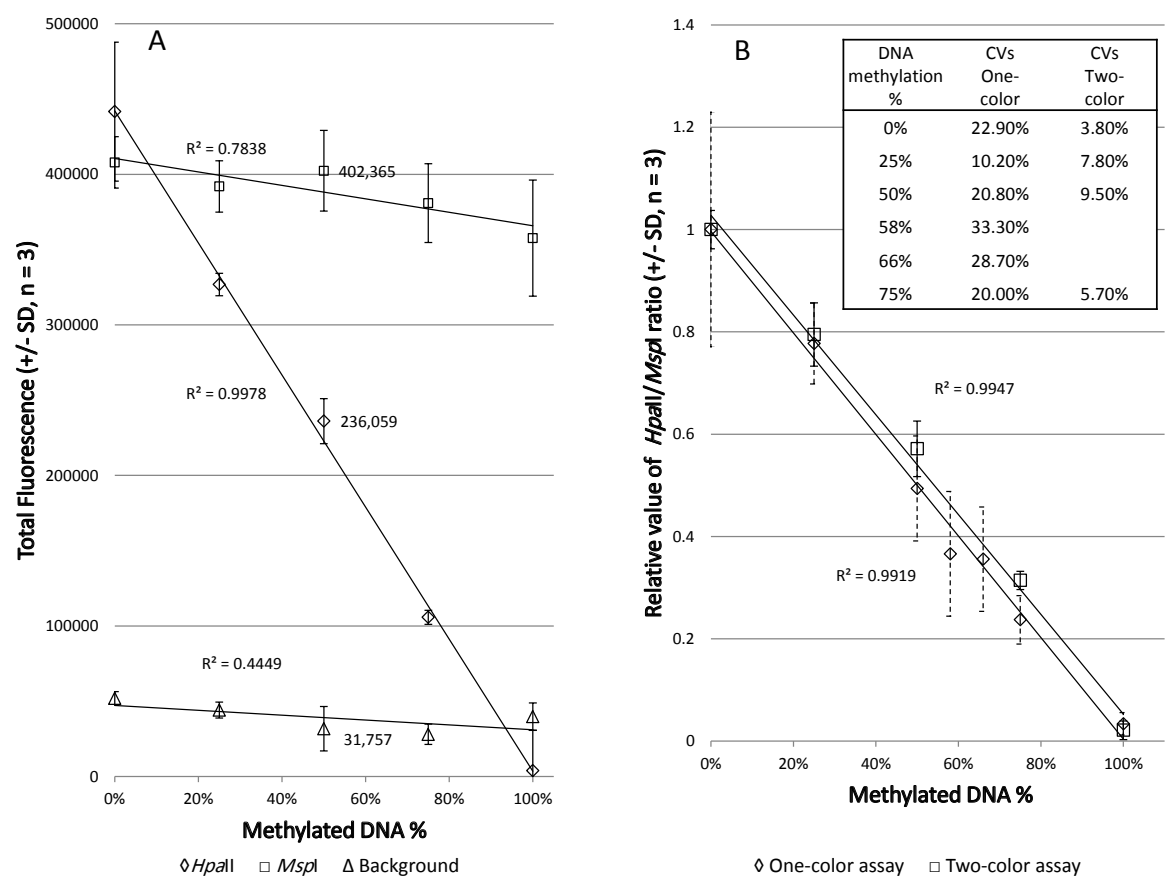

Figure 2. Regressions of Hpall and Mspl restriction digest fluorescence readings and of the one-color and two-color fluorescent cytosine extension assays (CEAs). (A) One-color fluorescent CEA across a methylated DNA serial dilution series. Data point values are indicated for the 50\% unmethylated/methylated DNA mixture. Single-step removal of unincorporated fluorescent nucleotides from the cytosine extension products of the two restriction digests were performed in separate columns. The undigested DNA background values $(\Delta)$ were subtracted from the values plotted for the Hpall $(\diamond)$ and $M s p l(\square)$ extension reactions. (B) Comparison of linear regression of the Hpall/Mspl ratio $\left(R^{2}\right)$ and precision (coefficient of variation; CV) of the one-color $(\diamond)$ and two-color $(\square)$ versions of the fluorescent CEA. Average $C V$ values for the measurements in the one-color and two-color analyses were $22.6 \%$ and $6.7 \%$, respectively $(P<$ 0.02 ; $t$-test), calculated from the combined data from two independent dilution series measured with onecolor assays and one dilution series measured with the two-color assay (CV data shown in table inset).

$\Sigma \mathrm{G} / \Sigma \mathrm{T}$ represent ratios of the sum of $\mathrm{G}$ peak heights and the sum of $\mathrm{T}$ peak heights in Hpall- and Mspl-digested DNA samples, respectively.

\section{Flow-cytometry assay}

Anti-5-methylcytosine antibody binding was measured in permeabilized, fixed cells using a method modified from Reference 21. Cells were harvested, washed with PBS-WB (1x DPBS, 0.1\% Tween-20, 1\% BSA), and fixed with $70 \%$ ethanol at $-20^{\circ} \mathrm{C}$. After a permeabilizing wash with PBS-TB ( $1 \times$ DPBS, $0.05 \%$ Triton X-100, 1\% BSA), $10^{6}$ cells were treated with $2 \mathrm{~N} \mathrm{HCL}$ for 30 min at room temperature and then neutralized with $0.2 \mathrm{M}$ phosphate buffer, pH 7.4. Immunostaining (1 h) was done by first incubating cells with mouse monoclonal anti-5-methylcytosine antibody NA81 (EMD Millipore, San Diego, CA), washing with PBS-TB, and then incubating the cells with goat anti-mouse secondary antibodies (30 min in the dark) coupled with Alexa Fluor 488 (Life Technologies, Burlington, ON, Canada). PBS-TB-washed cells were stained with propidium iodide $(5 \mu \mathrm{g} / \mathrm{mL})$. Fluorescence was detected by flow cytometry (Beckman Labcell Quanta;
Beckman Countler Canada, Mississauga, ON, Canada); settings: $488 \mathrm{~nm}$ excitation, $\mathrm{Pl}$ emission at $>620 \mathrm{~nm}$, Alexa Fluor 488 emission at $530 \pm 20 \mathrm{~nm})$. Data were analyzed using WinList software (Verity Software, Topsham, ME).

\section{Cell culture and DNA isolation}

Cell lines used in this study were: HepG2 (ATCC, Manassas, VA), derived from a welldifferentiated hepatocellular carcinoma; HepRG (Invitrogen), a human hepatomaderived hepatocyte progenitor cell line; and HC-04 (Biodefense and Emerging Infections Research Resources Repository, Manassas, VA), isolated from normal tissue surrounding a human hepatoma. Human biopsy cells were obtained from Celsis (Baltimore, MD). All cell lines were cultured according to the supplier's recommendations. DNA was isolated using the DNeasy Blood and Tissue kit from Qiagen. Human non-methylated and highly methylated HCT116 DNA was obtained from Zymo Research (Irvine, CA). DNA concentration was measured using a Nanodrop spectrophotometer (Thermo Fisher Scientific, Wilmington, DE).

\section{Results and discussion}

Specificity of the one-color and two-color assay formats

The assay was designed according to the general methods published for other singlelabel $(16-18,22)$ CEAs and modified into a dual-label assay as depicted in Figure 1. One-color and two-color assay performances were compared by measuring fluorescence intensity changes in serial mixtures of human unmethylated DNA and highly methylated DNA.

The linearity and precision of one-color fluorescent CEA using one-step removal of unincorporated fluorescent nucleotide was assessed. Fluorescence intensities of labeled DNA were similar for samples of either $100 \%$ methylated or unmethylated DNA digested with Mspl (Figure 2A). The fluorescence intensities we obtained were considered to be robust assay signals since the background signals from extension reactions of undigested DNA were only $6 \%$ of the total signals (background plus specific signal) from Mspl and Hpalldigested unmethylated DNA and 10\% of the smaller total signals obtained from the 1:1 (50\%) methylated mixture digested with Hpall. The signal-to-background ratio was greater than that reported for a similar single-label method for measuring DNA methylation by fluorescence polarization (22). Although the fluorescence polarization method is sensitive and has fewer steps than TCF-CEA (the extension reactions were not purified prior to polarization measurements), assay backgrounds in the absence of DNA were about equal to the signal when measuring $100 \mathrm{ng}$ of human genomic DNA. Higher signal-tobackground ratios in the TCF-CEA would allow more accurate measurement of smaller DNA samples.

As expected, methylation dilution curves demonstrated that Hpall only cut non-methylated DNA, while Mspl cut both methylated and unmethylated DNA, and ratios of fluorescence intensities were dependent upon the proportion of methylated DNA. A small but significant (linear regression test, $P<0.005$; $t$-test, $P$ $<0.07 ; 0 \%$ versus $100 \%$ methylated DNA) negative dose response ( $\approx 13 \%)$ in the $\mathrm{Mspl}$ channel indicated that the highly methylated DNA, prepared by reaction with M.Sssl methylase (23), may contain a small amount of off-site methylation at the external $\mathrm{C}$ in the recognition sequence CCGG, which cannot be cut by Mspl. M.Sssl methylase is 
known to catalyze cytosine deamination to uracil at a low rate when the methyl donor S-adenosyl-methionine (SAM) is limiting, removing the restriction site for $\mathrm{Mspl}$ digestion (24).

Fluorescent nucleotide extension was linear, with robust signals in the tested range of 60-500 ng genomic DNA (data not shown); 25 pg of labeled DNA, spotted on a microscope slide, was detectable using a microarray scanner (data not shown), suggesting that a substantial reduction in DNA sample size is possible, which would allow assay miniaturization. In the present study, 200 ng of each DNA sample, with 40 ng carried through to the protocol end, were chosen for further validation experiments.

To reduce variability below that found in the one-color fluorescent CEA, where digests are processed separately, the TCF-CEA version of the assay combined the two restriction enzyme digests into a single solution after cytosine extension. This modification was expected to reduce fluctuations in the fluorescence signals generated during the downstream processing steps. The $R^{2}$ value for the plotted Hpall/Mspl ratios along the dilution curve remained unchanged compared with the one-color assay (0.9947 compared with 0.9919), while the coefficient of variation (CV) decreased 3.5-fold from 0.226 to 0.0668 (Figure 2B). Therefore, both the one-color and two-color assays accurately reported the relatively large predetermined differences in sample methylation tested in these experiments. Importantly, the 3.5-fold improvement in precision gained by including the reference digest as a second color suggested that relatively smaller differences in methylation could be detected by TCF-CEA.

Signal fluctuations in separately processed restriction enzyme digests could have occurred in the one-color assay due to (i) differences in recovery of DNA during purification of the DNA digests after labeling by nucleotide extension, (ii) differences in the amounts of the Hpall and Mspl digests added individually to microplate wells, and/or (iii) well-to-well differences in reading the two fluorescence emissions. In TCF-CEA, co-processing fluorophore-labeled extension reactions and obtaining the ratio of fluorophore incorporation into the methylation sensitive/ insensitive digests in a single well helped normalize sample-to-sample variation due to measurement errors.
Sensitivity to small methylation differences

TCF-CEA sensitivity was assessed by determining the minimum methylation difference that could be detected between separate samples. Small amounts of serially diluted methylated DNA or unmethylated DNA were added to DNA from HepG2 cells (50\% methylated, as measured by LUMA), simulating small hyper- or hypo-methylation changes over ranges typically encountered in biological samples. TCF-CEA consistently detected as little as $7.5 \%$ hypo- or hyper-methylation relative to pure HepG2 DNA as a significant difference, when significance was corrected for multiple comparisons (Figure 3). Due to potential differences in reactivity and specific activity among lots of fluorophore-labeled dCTPs, similar standard curves for two-color extension labeling, generated from calibrated DNA sources, are necessary for the interpolation of unknown samples.

Estimation of DNA methylation levels among human hepatocellular sources Global DNA methylation levels were measured in DNA from three human cell lines (HepG2, HC-04, HepRG) and a primary culture of a human liver biopsy

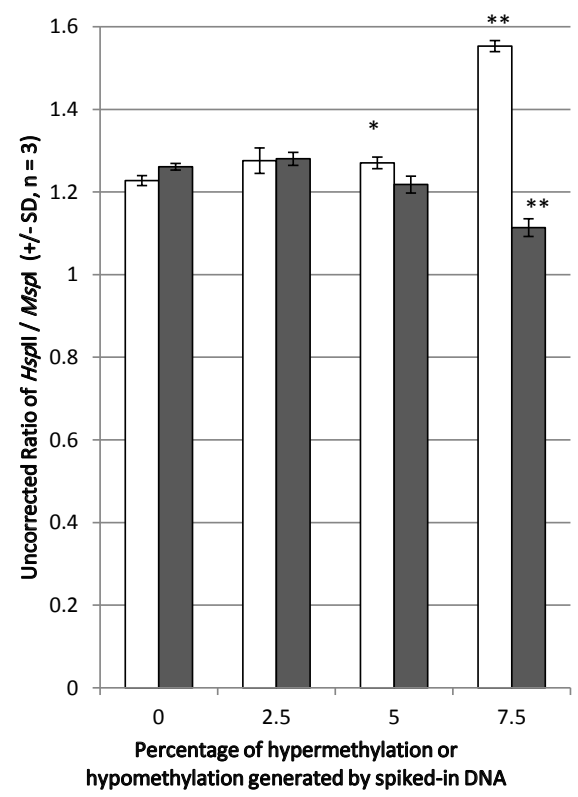

$\square$ unmethylated DNA spiked into HepG2 DNA

$\square$ methylated DNA spiked into HepG2 DNA

Figure 3. Evaluation of two-color cytosine extension assay (TCF-CEA) sensitivity to small differences in global DNA methylation. Hypomethylated or hypermethylated DNA from the HCT116 DKO cell line was serially diluted into HepG2 DNA. * $P<0.05 ;{ }^{* *} P<0.001 ; n=3$; t-test, two tailed, Bonferroni corrected. Average CV $=3 \%$. sample using TCF-CEA, and the results were compared with data from LUMA, a frequently employed global DNA methylation assay. Similar to TCF-CEA, LUMA detects differences in nucleotide extension $(\mathrm{dGTP}+\mathrm{dCTP})$ between DNA cleavages made by the Hpall and Mspl isoschizomers (19), but it uses pyrosequencing technology to detect these differences.

The results across the 4 different human liver cell cultures for both assays were highly correlated $\left(R^{2}=0.976\right.$; $\left.P<0.0001\right)$, and the degree of DNA methylation among the 4 cell types was significantly different (Figure 4A). For TCF-CEA, the CV values for the repeated measurements of the 4 DNA sources ranged 3\%-9\% (with a mean of $5 \%$ ), a range comparable to the $\mathrm{CV}$ values previously determined for the dilution series of methylated and unmethylated DNA (6.7\% and 3\%, in Figure 2B and Figure 3, respectively). Human liver biopsy cells showed the greatest DNA methylation, as expected, because the HepG2, HepRG, and HC-04 cell lines were all isolated from hepato-carcinomas $(25,26)$ or liver tumor-adjacent cells $(27)$, which usually exhibit DNA hypo-methylation (28). The 4 DNA sources spanned a range differing 34\% in methylation, from $73 \%$ of CCGG sites for the biopsy culture, which was comparable to the degree of DNA methylation measured in human fetal liver tissue (29), down to 39\% for $\mathrm{HC}-04$ cells, as measured by LUMA. The smallest difference detected by TCF-CEA was between HepG2 and HepRG cells ( $5 \%$, as measured by LUMA) and was comparable to the minimum differences detectable in the methylated DNA dilution series described above.

LUMA uses basically the same principles as a CEA, and the highly comparable relative DNA methylation results from the four different cell types confirmed that TCF-CEA provided reliable, semiquantitative measurements of genomic DNA methylation levels. It is interesting to note that similar ranges of methylation values have been measured by LUMA in peripheral blood DNA samples and have been associated with breast cancer risk $(20,30,31)$. Our results indicate that TCF-CEA could provide a simplified and accurate alternative to LUMA for detecting relative DNA methylation amounts in clinical and biobank samples, cultured cells after experimental treatments with toxins, or cell populations that have undergone oncogenic transformation or differentiation/dedifferentiation. 


\section{appliedbiosystems}
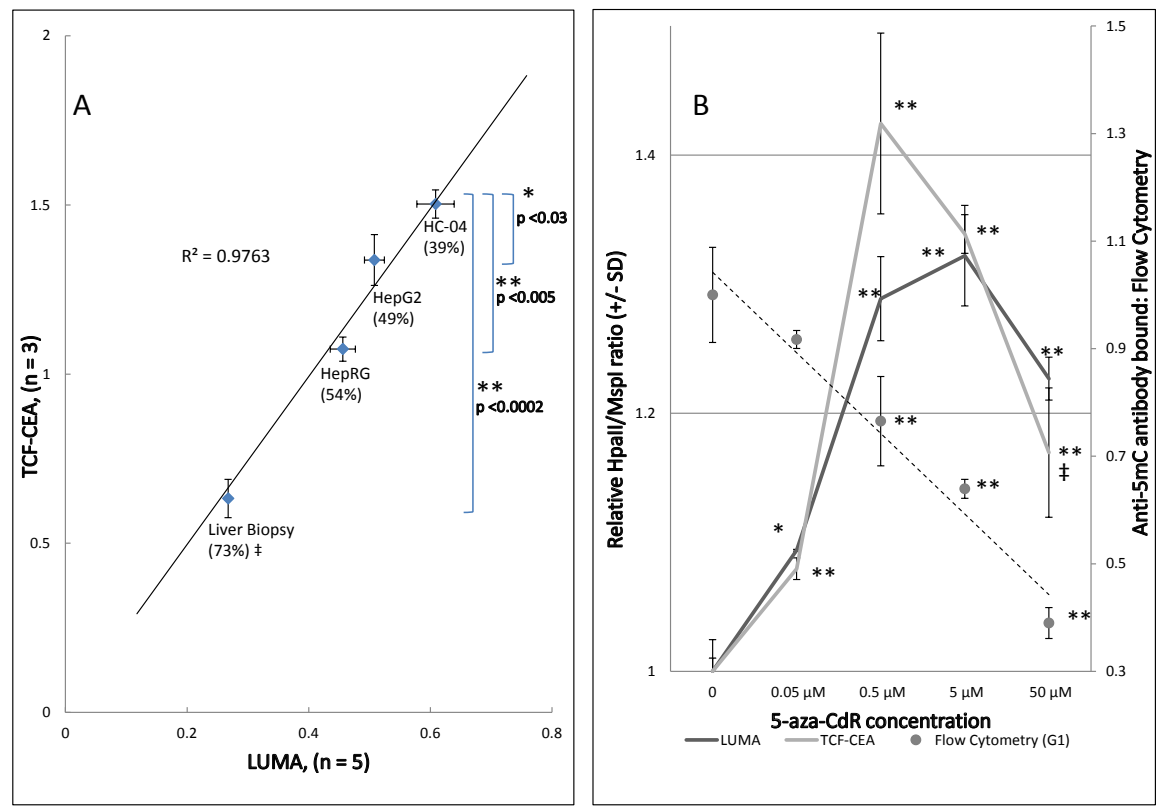

Figure 4. Comparison of the two-color cytosine extension assay (TCF-CEA) to other DNA methylation assays. (A) Comparison of the TCF-CEA and the LUminometric Methylation Assay (LUMA) estimates of global DNA methylation in primary human hepatic cells and hepatic cell lines. The $\mathrm{x}$ - and $\mathrm{y}$-axis values are, respectively, (Hpall/EcoRI)/(Mspl/EcoRI) and Hpall/ Mspl ratios ( $\pm S D$ ). The LUMA ratio on the $x$-axis indicates the fraction of CCGG unmethylation. Percentages of methylated CCGGs [1 - (Hpall/EcoRI)/(Mspl/EcoRI)*100], used as the index of global methylation from the LUMA assay, are shown within parentheses, while the TCF-CEA ratio is the ratio of incorporation of the two fluorophore-labeled dCTP nucleotides. $\ddagger$ = single LUMA measurement. Comparisons to HepG2 global DNA methylation determined by TCF-CEA are indicated to the right of the brackets; ${ }^{*} P<0.05 ; * * P<0.01$ (1-way ANOVA with Tukey's post-hoc test). $R^{2}=$ Pearson's correlation coefficient. Average CV values for the 4 TCF-CEA ratios were $5 \%$. (B) Three measures of global DNA methylation in HepG2 cells following a single demethylating treatment (5-aza-CdR) for $72 \mathrm{~h}$ (3 culture dishes for each exposure concentration in the TCF-CEA analysis and 5 culture dishes in the LUMA analysis). Both TCF-CEA and LUMA values are relative to the average of the untreated controls (1.00). Flow cytometry $\left( \pm\right.$ SD, $n=3$ cultures per treatment). ${ }^{*} P<0.05 ;{ }^{*} P<0.01$ (1-way ANOVA with Tukey's post-hoc test, comparison with untreated controls). $¥ P<0.01$ (LUMA and TCF-CEA; 1-way ANOVA with Tukey's post-hoc test, comparison with $0.5 \mu \mathrm{M}$ concentration).

The ability of TCF-CEA to detect altered DNA methylation levels in comparison to LUMA was confirmed in a second approach, following an experimental treatment of HepG2 cells with $0.05-50 \mu \mathrm{M}$ of the DNA demethylating agent 5-aza-2'-deoxycytosine (5-Aza-CdR) (Figure 4B). As expected, TCF-CEA showed increasing $\mathrm{Hpall} / \mathrm{Mspl}$ ratios compared with untreated cells in response to $0.05 \mu \mathrm{M}$ and $0.5 \mu \mathrm{M}$ 5-Aza-CdR. However, at the 2 highest concentrations of 5-Aza-CdR ( $5 \mu \mathrm{M}$ and $50 \mu \mathrm{M})$, the ratio substantially decreased compared with that obtained for $0.5 \mu \mathrm{M}$ treatment, with $50 \mu \mathrm{M}$ having a significantly lower ratio. A similar trend was also detected by LUMA. In contrast to the two restriction enzyme-based assays, antibody-based flow-cytometric detection of methylated deoxycytosine decreased continuously across the full range of 5-Aza-CdR concentrations. These data suggest interference with restriction enzyme site recognition by
5-Aza-CdR incorporation at high concentrations. Indeed, labeling of Hpall-digested DNA from cells treated with $5 \mu \mathrm{M}$ or $50 \mu \mathrm{M}$ 5-Aza-CdR was greatly reduced relative to the reference $\mathrm{Mspl}$-digested DNA, which was affected to a lesser extent, decreasing $\sim 30 \%$ relative to DNA from cells treated with $0.5 \mu \mathrm{M}$ 5-Aza-CdR (data not shown) Confounding effects of DNA adducts on restriction enzymes and polymerases need to be considered, such as the previously documented effects of benzo[a]pyrene adducts (32).

Several features of TCF-CEA would permit further assay development supporting higher throughput of DNA samples, such as in biobank specimen analyses or screening chemical libraries for compounds that affect global DNA methylation in cultured cells:

- Assay completion in $5 \mathrm{~h}$;

- Minimized variability by reducing processing steps and associated sources

\section{Uniquely designed for when precision is paramount}

The new Applied Biosystems ${ }^{\text {TM }}$ MicroAmp ${ }^{\text {TM }}$ 8-Tube Strip with attached optical or domed caps offers a combination of features designed to lead to a successful PCR/qPCR result every time.

- Individually attached caps

- Etched labeling on individual tubes

- Dual side tabs for strip labeling

- Graduated $20 \mu \mathrm{L}$ measuring markers

Available exclusively for Applied Biosystems $^{\text {TM }}$ thermal cyclers to provide optimal PCR results.

Take control of your PCR reactions at thermofisher.com/
microamptubestripswithcaps

\section{ThermoFisher S C I E N T I FIC}

For Research Use Only. Not for use in diagnostic procedures. (C) 2016 Thermo Fisher Scientific Inc. All rights reserved. All trademarks are the property of Thermo Fisher Scientific and its subsidiaries unless otherwise specified. COL21182 0416 
of error through (i) reducing DNA purification steps by combining two DNA digests into a single tube, (ii) reducing sample dispensation steps by performing extensions of Hpall and Mspl digests on one sub-sample of DNA, and (iii) reducing fluorescence measurement variability by obtaining both extension signals from a single multi-well plate per sample;

- No cytosine base modification requirement (e.g., bisulfite treatment);

- Cost-effective labeling and detection because (i) standard laboratory equipment is used for fluorescence detection and (ii) labeling with fluorescent nucleotides is highly efficient. For example, $0.05 \mu \mathrm{mol}$ of each commercially available Alexamodified dCTP is sufficient for 5000 assays - when using 5 pmol per extension step with 1 background extension for each uncut DNA sample plus a corresponding extension of DNA cut with a methylationsensitive or -insensitive restriction enzyme (Figures 1 and 3). The total assay number per fluorescent nucleotide lot could be increased several-fold by assay miniaturization and reduction of the amount of DNA sample required.

- Extension reactions in multi-well plates could be coupled to product purification in a multi-well format to facilitate automated processing.

\section{Author contributions}

C.P. conceived and designed the methodology and experiments. C.P. and D.D. were responsible for funding acquisition and project management. G.Z., C.C.-L., and G.-H.X. performed the experiments and collected the data. C.P., G.Z., and C.C.-L. analyzed the data. D.D. contributed reagents and materials. C.P., G.Z., and C.C.-L. wrote the paper.

\section{Acknowledgments}

Funding was provided by the Chemicals Management Plan of the Government of Canada. We thank Lawton Stubbert for advice during initial experiments on flow cytometric detection of methylated cytosine in DNA.

\section{Competing interests}

The authors declare no competing interests.

\section{References}

1. Woo, H.D. and J. Kim. 2012. Global DNA hypomethylation in peripheral blood leukocytes as a biomarker for cancer risk: A meta-analysis. PLoS One 7:e34615.
2. Brennan, K. and J.M. Flanagan. 2012. Is there a link between genome-wide hypomethylation in blood and cancer risk? Cancer Prev. Res. (Phila.) 5:1345-1357

3. Dawson, M.A. and T. Kouzarides. 2012. Cancer epigenetics: From mechanism to therapy. Cell 150:12-27.

4. Tsai, H.C. and S.B. Baylin. 2011. Cancer epigenetics: Linking basic biology to clinical medicine. Cell Res. 21:502-517.

5. Herceg, Z. and T. Vaissière. 2011. Epigenetic mechanisms and cancer an interface between the environment and the genome. Epigenetics 6:804-819.

6. Portela, A. and M. Esteller. 2010. Epigenetic modifications and human disease. Nat. Biotechnol. 28:1057-1068.

7. Hou, L., X. Zhang, D. Wang, and A. Baccarelli. 2012. Environmental chemical exposures and human epigenetics. Int. J. Epidemiol. 41:79-105.

8. Ogino, S., P. Lochhead, A.T. Chan, R. Nishihara, E. Cho, B.M. Wolpin, J.A. Meyerhardt, A. Meissner, et al. 2013. Molecular pathological epidemiology of epigenetics: Emerging integrative science to analyze environment, host, and disease. Mod. Pathol. 26:465-484.

9. Pogribny, I.P. and I. Rusyn. 2013. Environmental toxicants, epigenetics, and cancer. Adv. Exp. Med. Biol. 754:215-232.

10. Umer, M. and Z. Herceg. 2013. Deciphering the epigenetic code: An overview of DNA methylation analysis methods. Antioxid. Redox Signal. 18:19721986.

11. Kurdyukov, S. and M. Bullock. 2016. DNA methylation analysis: Choosing the right method. Biology (Basel) 5:3

12. Lander, E.S., L.M. Linton, B. Birren, C. Nusbaum, M.C. Zody, J. Baldwin, K. Devon, K. Dewar, et al. 2001. Initial sequencing and analysis of the human genome. Nature 409:860-921.

13. Lindsay, S. and A.P. Bird. 1987. Use of restriction enzymes to detect potential gene sequences in mammalian DNA. Nature 327:336-338.

14. Deaton, A.M. and A. Bird. 2011. CpG islands and the regulation of transcription. Genes Dev. 25:1010-1022

15. Rollins, R.A., F. Haghighi, J.R. Edwards, R. Das, M.Q. Zhang, J. Ju, and T.H. Bestor. 2006. Largescale structure of genomic methylation patterns. Genome Res. 16:157-163.

16. Pogribny, I., P. Yi, and S.J. James. 1999. A sensitive new method for rapid detection of abnormal methylation patterns in global DNA and within $\mathrm{CpG}$ islands. Biochem. Biophys. Res. Commun. 262:624-628.

17. Fujiwara, H. and M. Ito. 2002. Nonisotopic cytosine extension assay: A highly sensitive method to evaluate $\mathrm{CpG}$ island methylation in the whole genome. Anal. Biochem. 307:386-389.

18. Anisowicz, A., H. Huang, K.I. Braunschweiger, Z. Liu, H. Giese, H. Wang, S. Mamaev, J. Olejnik, et al. 2008. A high-throughput and sensitive method to measure Global DNA Methylation: Application in Lung Cancer. BMC Cancer 8:222.

19. Karimi, M., S. Johansson, D. Stach, M. Corcoran, D. Grandér, M. Schalling, G. Bakalkin, F. Lyko, et al. 2006. LUMA (LUminometric Methylation Assay)-A high throughput method to the analysis of genomic DNA methylation. Exp. Cell Res. 312:1989-1995.

20. Bjornsson, H.T., M.I. Sigurdsson, M.D. Fallin, R.A. Irizarry, T. Aspelund, H. Cui, W. Yu, M.A. Rongione, et al. 2008. Intra-individual change over time in DNA methylation with familial clustering. JAMA 299:2877-2883.

21. Habib, M., F. Fares, C.A. Bourgeois, C. Bella, J. Bernardino, F. Hernandez-Blazquez, A. De Capoa, and A. Niveleau. 1999. DNA global hypomethylation in EBV-transformed interphase nuclei. Exp. Cell Res. 249:46-53.

22. Zhao, C. and H. Xue. 2012. A simple method for high-throughput quantification of genome-wide DNA methylation by fluorescence polarization. Epigenetics 7:335-339.

23. Nur, I., M. Szyf, A. Razin, G. Glaser, S. Rottem and S. Razin. 1985. Procaryotic and eucaryotic traits of DNA methylation in spiroplasmas (mycoplasmas). J. Bacteriol. 164:19-24.

24. Stier, I. and A. Kiss. 2013. Cytosine-to-Uracil Deamination by SssI DNA Methyltransferase. PLoS One 8:e79003.

25. Aden, D.P., A. Fogel, S. Plotkin, I. Damjanov, and B.B. Knowles. 1979. Controlled synthesis of HBsAg in a differentiated human liver carcinomaderived cell line. Nature 282:615-616.

26. Guillouzo, A., A. Corlu, C. Aninat, D. Glaise, F. Morel, and C. Guguen-Guillouzo. 2007. The human hepatoma HepaRG cells: A highly differentiated model for studies of liver metabolism and toxicity of xenobiotics. Chem. Biol. Interact. 168:66-73.

27. Sattabongkot, J., N. Yimamnuaychoke, S. Leelaudomlipi, M. Rasameesoraj, R. Jenwithisuk, R.E. Coleman, R. Udomsangpetch, L. Cui, and T.G. Brewer. 2006. Establishment of a human hepatocyte line that supports in vitro development of the exo-erythrocytic stages of the malaria parasites Plasmodium falciparum and P. vivax. Am. J. Trop. Med. Hyg. 74:708-715.

28. Pogribny, I.P. and I. Rusyn. 2014. Role of epigenetic aberrations in the development and progression of human hepatocellular carcinoma. Cancer Lett. 342:223-230.

29. Nahar, M.S., C. Liao, K. Kannan, C. Harris, and D.C. Dolinoy. 2015. In utero bisphenol A concentration, metabolism, and global DNA methylation across matched placenta, kidney, and liver in the human fetus. Chemosphere 124:54-60.

30. McCullough, L.E., J. Chen, A.J. White, X Xu, Y.H. Cho, P.T. Bradshaw, S.M. Eng, S.L. Teitelbaum, et al. 2015. Global DNA Methylation, Measured by the Luminometric Methylation Assay (LUMA), Associates with Postmenopausal Breast Cancer in Non-Obese and Physically Active Women. J. Cancer 6:548-554.

31. Xu, X., M.D. Gammon, H. Hernandez-Vargas, Z. Herceg, J.G. Wetmur, S.L. Teitelbaum, P.T. Bradshaw, A.I. Neugut, et al. 2012. DNA methylation in peripheral blood measured by LUMA is associated with breast cancer in a populationbased study. FASEB J. 26:2657-2666.

32. Sadikovic, B., J. Andrews, and D.I. Rodenhiser. 2007. DNA methylation analysis using CpG microarrays is impaired in benzopyrene exposed cells. Toxicol. Appl. Pharmacol. 225:300-309.

Received 08 November 2016; accepted 07 February 2017.

Address correspondence to Craig Parfett, Mechanistic Studies Division, Environmental Health Science and Research Bureau, HECSB, Health Canada, Ottawa. E-mail: craig.parfett@canada.ca

To purchase reprints of this article, contact: biotechniques@fosterprinting.com 